\title{
Análise comparativa de geocoberturas em três vertentes no Chapadão do Diamante, Serra da Canastra-MG, Brasil
}

\author{
Comparative analysis of three slopes in Chapadão do Diamante, \\ Serra da Canastra-MG, Brazil
}

Thallita Isabela Silva Martins Nazar Doutora em Geografia pela Universidade Federal de Uberlândia thallitamartins09@gmail.com

Silvio Carlos Rodrigues

Prof. Dr. Em Geografia - IG/UFU

silgel@ufu.br

\begin{abstract}
Resumo
O presente artigo tem por objetivo a caracterização física de três vertentes representativas do Chapadão do Diamante, na Serra da Canastra, tendo em vista a diversidade de formas de relevo e de geocoberturas ali presentes. A aplicação das análises laboratoriais de granulometria contribuiu para a caracterização morfológica dos materiais, para o melhor entendimento dos processos físicos atuantes durante a sua gênese. Foram aplicadas técnicas de peneiramento e sedimentação, que permitiram uma importante diferenciação entre as três vertentes analisadas, além da elaboração de curvas granulométricas para cada camada nos diferentes pontos amostrais a partir do peneiramento, sendo que os dados oriundos da sedimentação foram lançados no triângulo textural. Os resultados demonstraram, também, variações dentro dos próprios transectos, indicando respostas dos materiais às características do terreno e do substrato.
\end{abstract}

Palavras-chave: Granulometria, materiais superficiais, geomorfologia.

\begin{abstract}
This article aims at the physical characterisation of three representative slopes of the Chapadão do Diamante, in Serra da Canastra, given the diversity of landforms and geocovers present there. The application of particle size analysis contributed to the morphological characterisation of the materials, to a better understanding of the physical processes acting during their genesis. Gradation and sedimentation techniques were applied, which allowed a critical differentiation between the three slopes analysed, besides the elaboration of particle size curves for each layer in the different sampling points from the sieve analysis, and the data from the sedimentation were placed in the textural triangle. The results also showed variations within the transects themselves, indicating materials responses to the terrain and substrate characteristics.
\end{abstract}

Keywords: Particle size analysis; surface materials; geomorphology.

\section{INTRODUÇÃO}

O Chapadão do Diamante (ChD), enquanto superfície de cimeira da Serra da Canastra, pode ser analisado, conforme Nazar e Rodrigues (2019b), a partir da inter-relação entre os seus aspectos litoestruturais, formas de relevo e geocoberturas. Estas últimas são consideradas pelos autores supracitados como 
todos os materiais que constituem o manto de alteração superficial que recobre o relevo da Terra, originados por processos físicos ou químicos, in situ ou por transporte e deposição, incluindo os materiais inconsolidados e móveis, bem como os consolidados, por exemplo, os afloramentos rochosos, já expostos aos processos de intemperismo (NAZAR; RODRIGUES, 2019b, p. 3).

Neste sentido, ao observar a existência de um conjunto de três eixos estruturais que se diferenciam na superfície, principalmente em função dos tipos de formas e geocoberturas recorrentes em cada eixo, Nazar e Rodrigues (2019b) apresentam o mapeamento das geocoberturas, e reiteram que o substrato rochoso (quartzitos puros a micáceos e filitos) pode condicionar os distintos padrões de formas de relevo e consequentemente, os tipos de materiais sobrejacentes.

Do ponto de vista geomorfológico, pode-se dizer que o Chapadão do Diamante é subdividido em áreas de cristas quartzíticas e afloramentos rochosos abundantes, os quais expressam a ocorrência do quartzito puro; e em áreas de relevos dissecados, com colinas que variam de suaves, onduladas a fortemente onduladas, associados aos tipos rochosos de quartzitos micáceos e filitos (NAZAR, 2018; NAZAR; RODRIGUES, 2019a; 2019b, SOUZA;RODRIGUES, 2014).

Tendo em vista a diversidade morfológica e de geocoberturas reconhecidas para o Chapadão do Diamante, o presente trabalho buscou a caracterização de três vertentes amostrais em diferentes padrões de paisagem existentes, considerando-as representativas para uma aproximação da compreensão da dinâmica geomorfológica da área, sendo o entendimento de tais diferenças um avanço para o conhecimento científico do Chapadão do Diamante.

\section{PROCEDIMENTOS METODOLÓGICOS}

Foram selecionadas três áreas amostrais para a realização de coletas de materiais superficiais, baseadas em transectos ao longo do eixo interflúvio-fundo de vale, em três tipos principais de vertentes (Figura 1).

A escolha dos transectos pautou-se em critérios empíricos, a priori, porém estão de acordo com as diferentes classes de relevo mapeadas por Nazar e Rodrigues (2019a). O intuito de tal escolha foi estabelecer as relações entre o relevo e as geocoberturas, conforme os principais padrões de paisagem observados inicialmente:

- Primeiro padrão observado, onde o relevo caracteriza-se por formas mais íngremes, geralmente associados às áreas de afloramentos quartzíticos, cujos materiais superficiais são de pequena espessura, ora com presença de cascalhos, ora com material mais fino. Presença de vegetação do tipo campo rupestre (TRANSECTO A).

- $\quad$ Segundo padrão verificado, no qual o relevo torna-se suave ondulado, com raros afloramentos, e as geocoberturas variam de espessura, com presença de concreções ferruginosas nos 
topos, predominando frações cascalho-arenosas; e ocorrência de campos de murunduns em diversas posições topográficas, preferencialmente em trechos retilíneos e côncavos; e nos fundos dos vales podem ser observados materiais finos a grosseiros na cor acinzentada escura, associada à lenta decomposição da matéria orgânica, que permanece por mais tempo no ambiente. Presença de vegetação do tipo campo limpo a sujo (TRANSECTO B).

- Terceiro padrão observado, em que o relevo se apresenta plano a suave ondulado, com ocorrência de materiais espessos na cor avermelhada e com presença de concreções ferruginosas, em área mais afastada dos afloramentos quartzíticos. Os campos de murunduns também se fazem presentes e fundo de vales com materiais orgânicos. Presença de vegetação do tipo campo limpo, campo sujo a cerrado stricto sensu (TRANSECTO C).

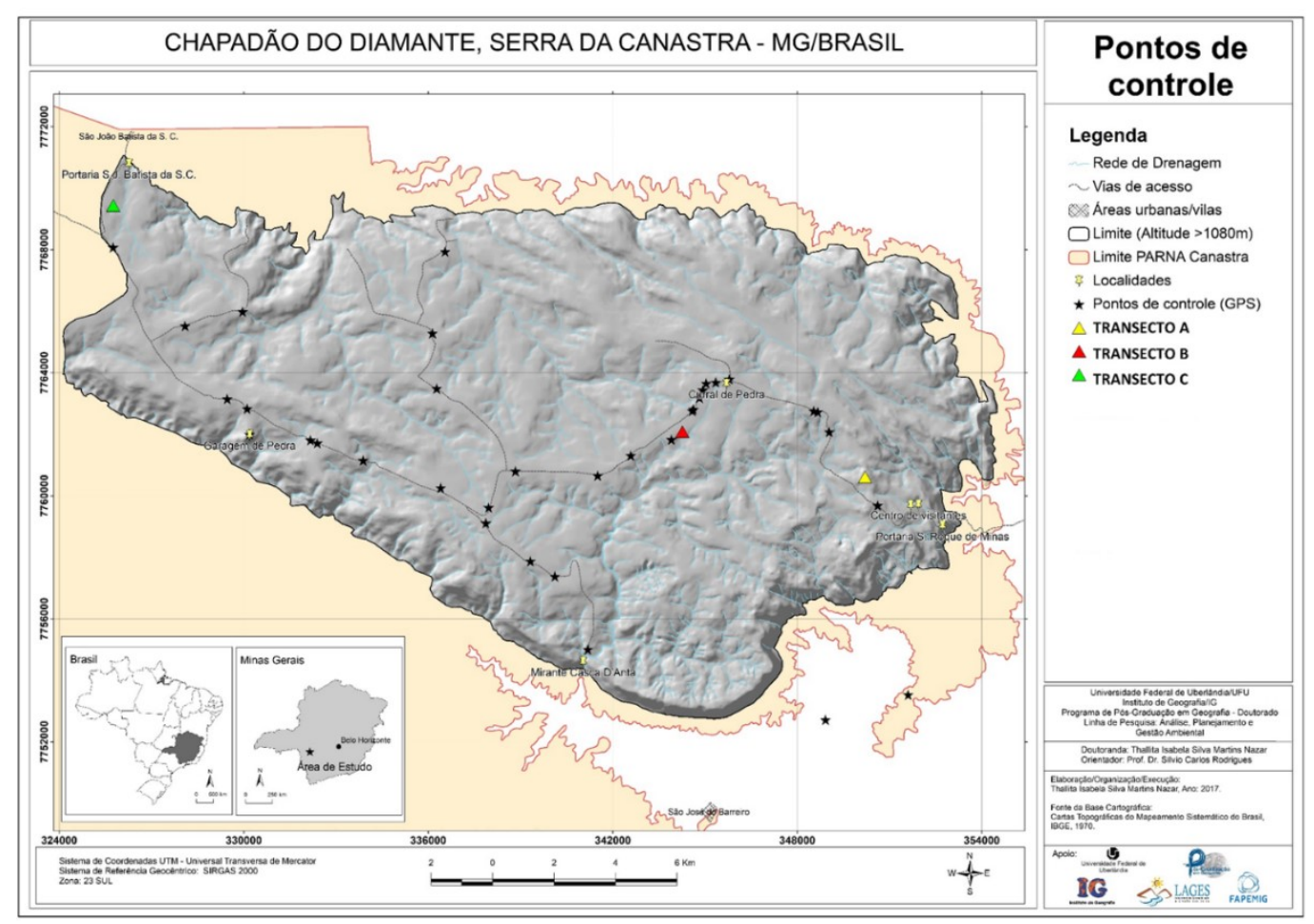

Figura 1 - Localização das áreas amostrais. Fonte: Autores, 2018.

É importante ressaltar, conforme salienta Messias-Martins et al. (2013), que na análise geomorfológica a abordagem vai além da interpretação pedológica das coberturas terrestres, sendo, portanto, viabilizado a substituição dos termos "solo" e "horizontes" por materiais superficiais e camadas, respectivamente, sendo adotado para este trabalho o termo geocoberturas.

Neste sentido, os transectos foram georreferenciados a partir da tomada dos pontos de controle por GPS, tendo sido plotados sobre o MDT, com o intuito de gerar o perfil topográfico de cada um deles. Os pontos para coleta de amostras e descrições dos perfis e camadas dos materiais foram selecionados conforme a divisão em alta, média e baixa vertente, bem como as mudanças 
gradativas de gradiente, coloração, espessura e tipo de material subjacente. Executou-se tradagens com trado holandês e, quando se julgou necessário, foram abertas pequenas trincheiras para averiguação das características. As amostras foram dispostas em saquinhos plásticos, devidamente marcadas e acondicionadas em caixa organizadora.

Para as análises físicas das geocoberturas do $\mathrm{ChD}$, adotou-se os ensaios de peneiramento e sedimentação para as amostras recolhidas a partir dos três transectos já descritos, uma vez que a curva de distribuição granulométrica indica as características físicas dos materiais superficiais, e oferece indícios do comportamento da vertente. Assim, foram elaboradas curvas granulométricas para cada camada nos diferentes pontos amostrais, a partir do peneiramento, e os dados oriundos da sedimentação foram lançados no triângulo textural. Tais procedimentos foram realizados no Laboratório de Geomorfologia e Erosão dos Solos - LAGES, na Universidade Federal de Uberlândia, seguindo o Procedimento Operacional Padrão (POP) conforme Santos e Rodrigues (2019) com base nas metodologias da Embrapa (1997, 2012).

Os diferentes tipos de curvas granulométricas, as quais podem indicar se o material possui granulometria contínua ou descontínua, se é uniforme, bem graduado ou mal graduado; permitem reconhecer as características que podem indicar os processos predominantes ao longo das vertentes. E as classes texturais, tomadas pelo triângulo, foram utilizadas como complemento à análise para melhor caracterizar as geocoberturas, bem como estabelecer a certo nível, a intensidade do intemperismo, que pode ser complementada pela proporção de argila, já que esta faz parte dos últimos estágios da ação intempérica.

\section{RESULTADOS E DISCUSSÃO}

A aplicação das análises laboratoriais de granulometria contribuiu para a caracterização morfológica dos materiais, além de confluir para o melhor entendimento dos graus de intemperismo nos três ambientes, a partir da identificação dos constituintes da fração argila, assim como os processos físicos atuantes durante a gênese de tais materiais.

Em relação às análises granulométricas, tanto por peneiramento quanto por sedimentação, observou-se diferentes padrões entre as três vertentes analisadas. Os resultados demonstraram, também, variações dentro dos próprios transectos, indicando respostas dos materiais às características do terreno e do substrato.

\subsection{Transecto A}

A primeira área amostral compreende o transecto A (Figura 2), realizado em relevo de cristas quartzíticas, com afloramentos rochosos contínuos no topo e caos de blocos com materiais cascalho-arenosos nas médias vertentes. Em alguns locais, ocorre deposição de material por 
coluvionamento, os quais são barrados pela ocorrência de caos de blocos, e às vezes são recobertos com camada superficial hidromórfica. Esta vertente, localizada a NE do ChD, perfaz uma distância de 500 metros do topo até a base, com trechos convexo-retílíneos e côncavos. Ao longo do transecto, foram realizados 7 pontos de coleta por tradagens e pequenas trincheiras.

No que se refere à análise granulométrica por peneiramento, de modo geral, as granulometrias fornecem curvas descontínuas e mal graduadas, coincidindo com as observações em campo, sendo predominantes as frações de cascalhos e areias. Estas condições permitem associar à prevalência de processos mecânicos atuantes sobre as rochas quartzíticas puras, que no local, constituem vertentes mais declivosas. As pequenas espessuras dos pacotes de materiais, em tal transecto, reiteram esta situação. Em contrapartida, nos locais amostrais onde se caracterizam áreas de deposição, em função das barreiras formadas pelos próprios afloramentos rochosos ou em áreas côncavo-retilíneas, as curvas granulométricas se mostram um pouco mais contínuas e pouco mais graduadas. A Figura 2 ilustra os conjuntos de curvas granulométricas, representadas através de escala logarítmica, para cada ponto amostral, indicando a variação em cada camada.

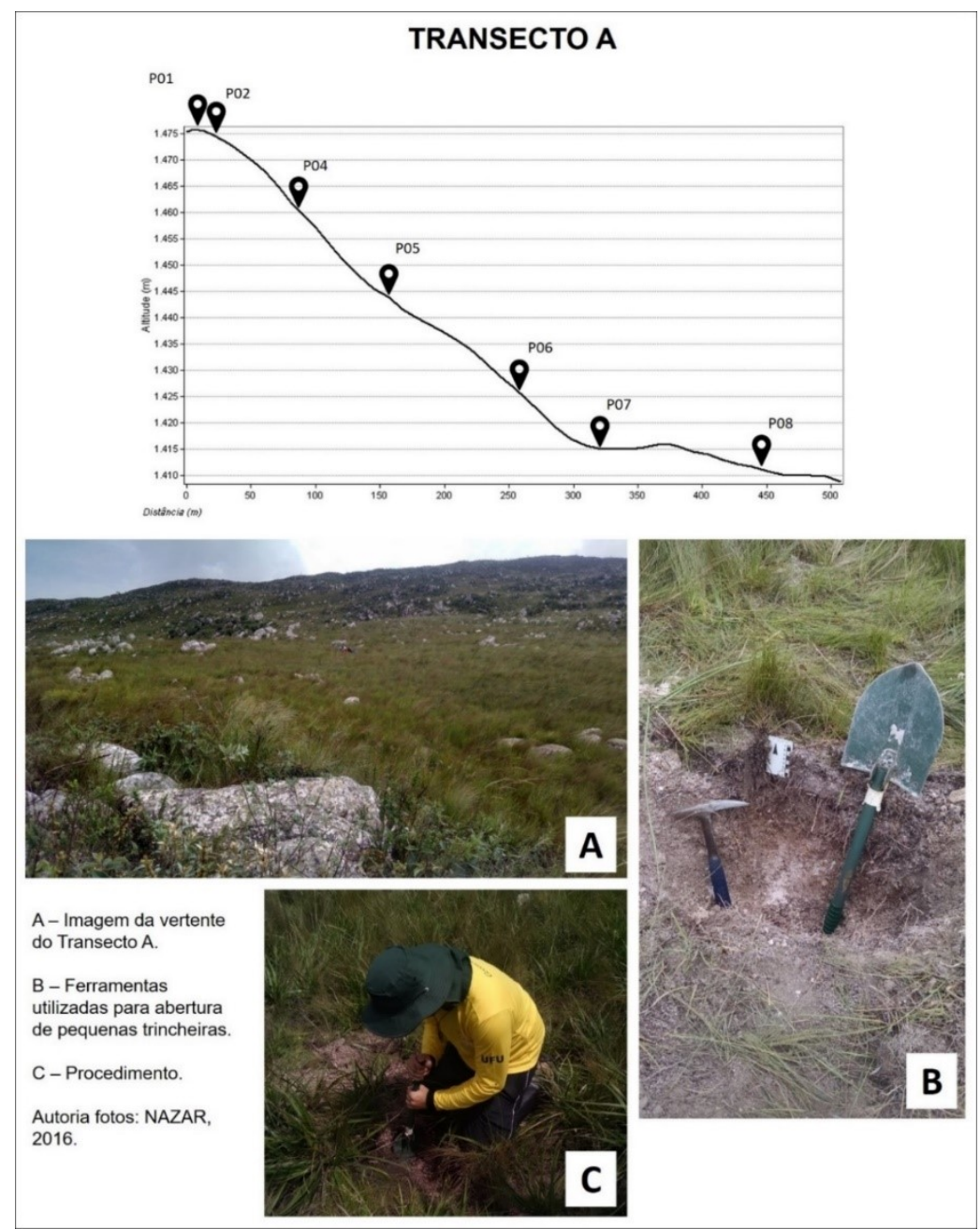

Figura 2 - Transecto A e pontos amostrais.

Fonte: Autores, 2018. 
Observa-se que as curvas da Figura 3 referentes a alta vertente (Pontos 1 a 4 ) fogem completamente ao formato próximo de "S", ao mesmo tempo em que a porcentagem das frações passantes mostra o predomínio dos grãos grosseiros (localizados entre os valores logarítmicos 1 e 10).

Por sua vez, as curvas dos pontos da média vertente apresentam uma anomalia nas amostras com profundidade superior a $32-33 \mathrm{~cm}$, o que provavelmente indica a presença de rocha alterada a partir desta profundidade. Os pontos 5 e 6 estão localizados em áreas de deposição coluvial, o primeiro reflete materiais cascalho-arenosos na camada superior, enquanto o segundo demonstra uma camada superficial de material contínuo e bem graduado. Estas diferenças podem indicar que os materiais mais grosseiros são barrados nas partes mais altas da vertente. Ao mesmo tempo, os materiais mais finos passam a ser retrabalhados e são expostos mais facilmente à ação do intemperismo.

No caso da baixa vertente, o ponto 7 apresenta uma camada superior mais fina com curva contínua, sobreposta a uma camada bastante cascalhenta, com profundidade de 7 a $24 \mathrm{~cm}$. Esta segunda camada grosseira pode ser associada às correspondentes nos dois pontos a montante (Ponto 5 e 6), os quais demonstram em profundidades próximas, um aumento da fração areia grossa e cascalho, subjacentes a uma camada mais homogênea e fina. Estas características podem indicar mudanças nos processos que ocorreram/ocorrem em função de variações climáticas. Já o ponto 8 caracterizado por uma área com gradientes suaves, apresenta curvas mais continuas nas camadas superiores, com ocorrência de cascalhos após os $28 \mathrm{~cm}$ de profundidade.

A respeito das análises granulométricas por sedimentação, apresenta-se os gráficos da distribuição da granulação fina dos materiais, bem como o triângulo textural (Figura 4), a partir dos quais, verifica-se a preponderância das frações arenosas. De modo geral, julga-se que o transecto A da vertente localizada em área de cristas quartzíticas deve ser caracterizado como predominantemente cascalho-arenoso, com a fração fina franco-arenosa. 

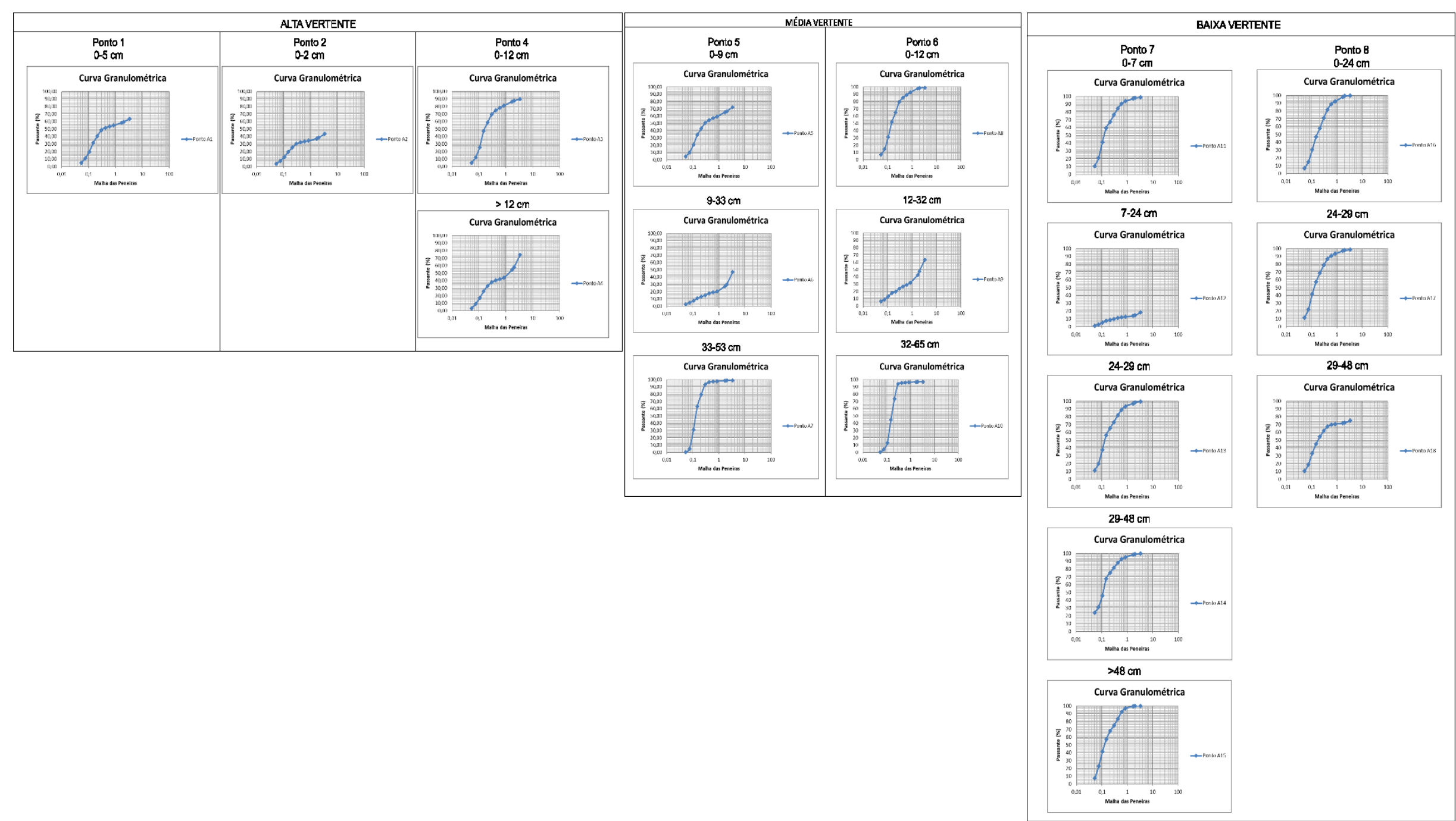

Figura 3 - Curvas granulométricas dos pontos amostrais do Transecto A.

Fonte: Autores, 2018. 


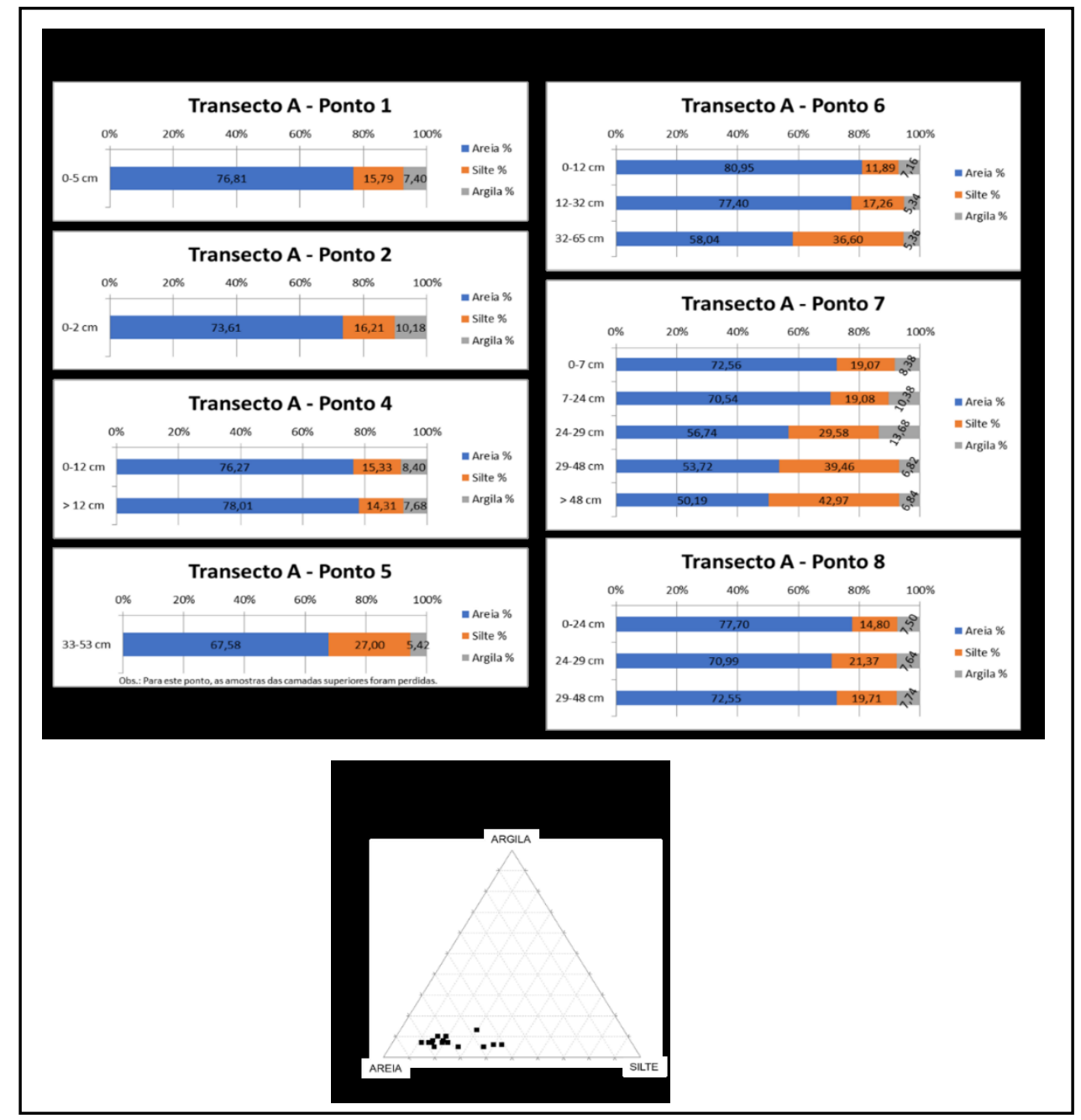

Figura 4 - Conjunto de gráficos e triângulo textural, resultantes da análise de granulometria por sedimentação para o Transecto A (Fonte: Autores, 2018).

\subsection{Transecto B}

A segunda área engloba o transecto B (Figura 5), traçado em relevo aplainado a suavemente dissecado com raros afloramentos e camadas estreitas de materiais cascalhentos e concrecionários no topo, passando por campo de murunduns na média vertente e materiais turfosos no fundo de vale. Ao longo das seções de alta e média vertentes, foram observadas ocorrências de cascalhos com concreções ferruginosas, bem como camada endurecida como laterita, de difícil tradagem. Esta vertente possui cerca de 600 metros, com trechos convexo-retilíneos e côncavoretilíneos, estando localizada na parte centro-leste do $\mathrm{ChD}$. Foram realizados 13 pontos de coleta por meio de tradagens e abertura de algumas pequenas trincheiras.

As análises granulométricas por peneiramento demonstraram para a vertente B uma relevante variação nas curvas em cada ponto amostral. Em sua maioria, os gráficos indicam curvas granulométricas descontínuas e mal graduadas, como é o caso da alta vertente, onde ocorrem cascalhos com concreções ferruginosas em material bastante avermelhado nas camadas superficiais. É possível observar, também, em área de ocorrência de murunduns, uma camada subsuperficial 
composta por material ferruginoso cascalhento, indicando que a camada superior com grãos mais finos, pode ser resultante de atividade de bioturbação (Figura 6).

Em relação à variação na média vertente, é possível observar que após $18 \mathrm{~cm}$ de profundidade no ponto 4, ocorre uma camada cascalhenta com concreções ferruginosas. Observa-se uma descontinuidade dessa camada ferruginosa, que volta a parecer, à jusante da média vertente (ponto 7), e na transição para a baixa vertente (ponto 8), por vezes, impenetrável por tradagem, indicando a presença de laterita endurecida. Tal descontinuidade é verificada a partir de uma ruptura e declive, com afloramentos de quartzito a montante e de filito a jusante.

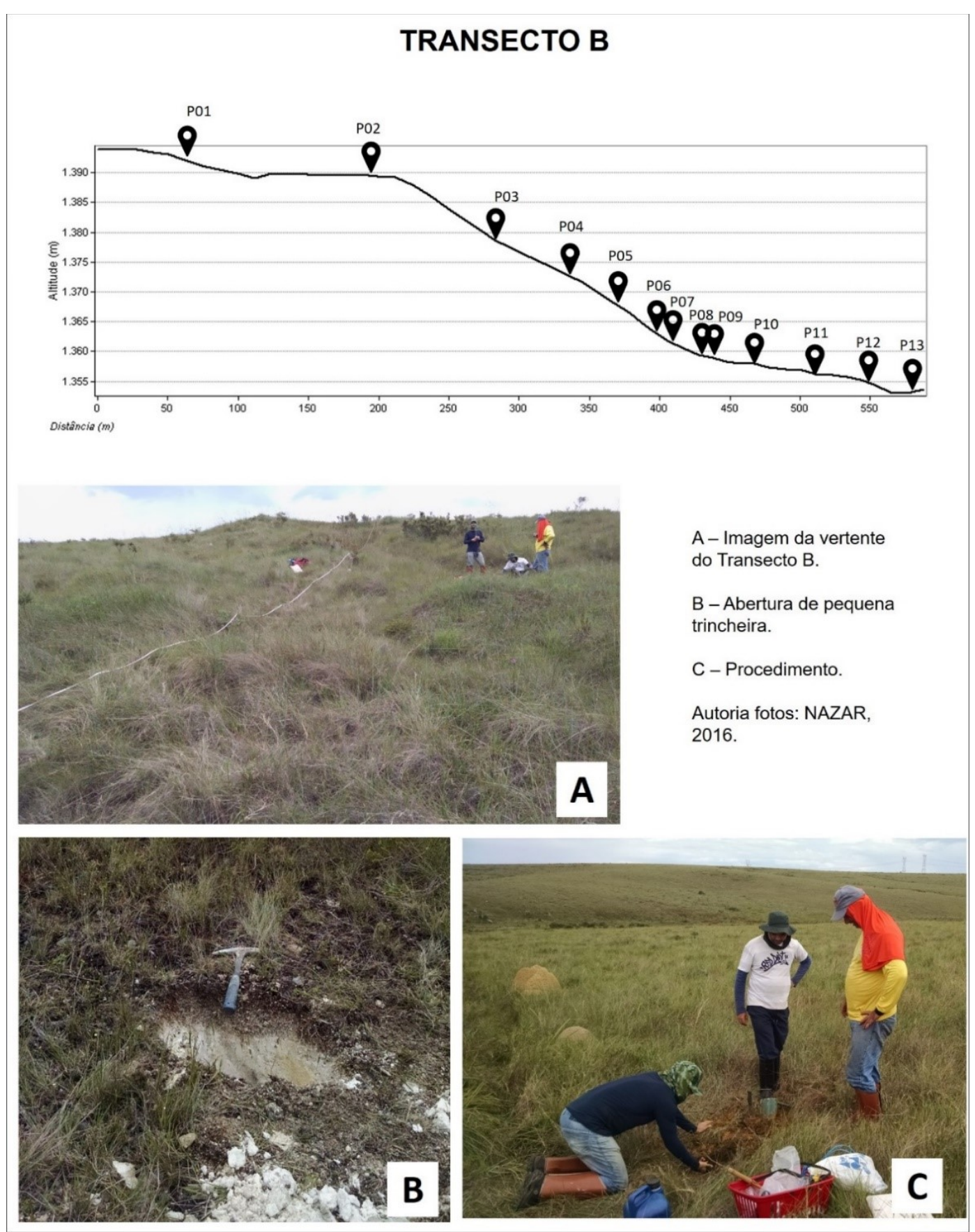

Figura 5 - Transecto B e pontos amostrais. Fonte: Autores, 2018. 

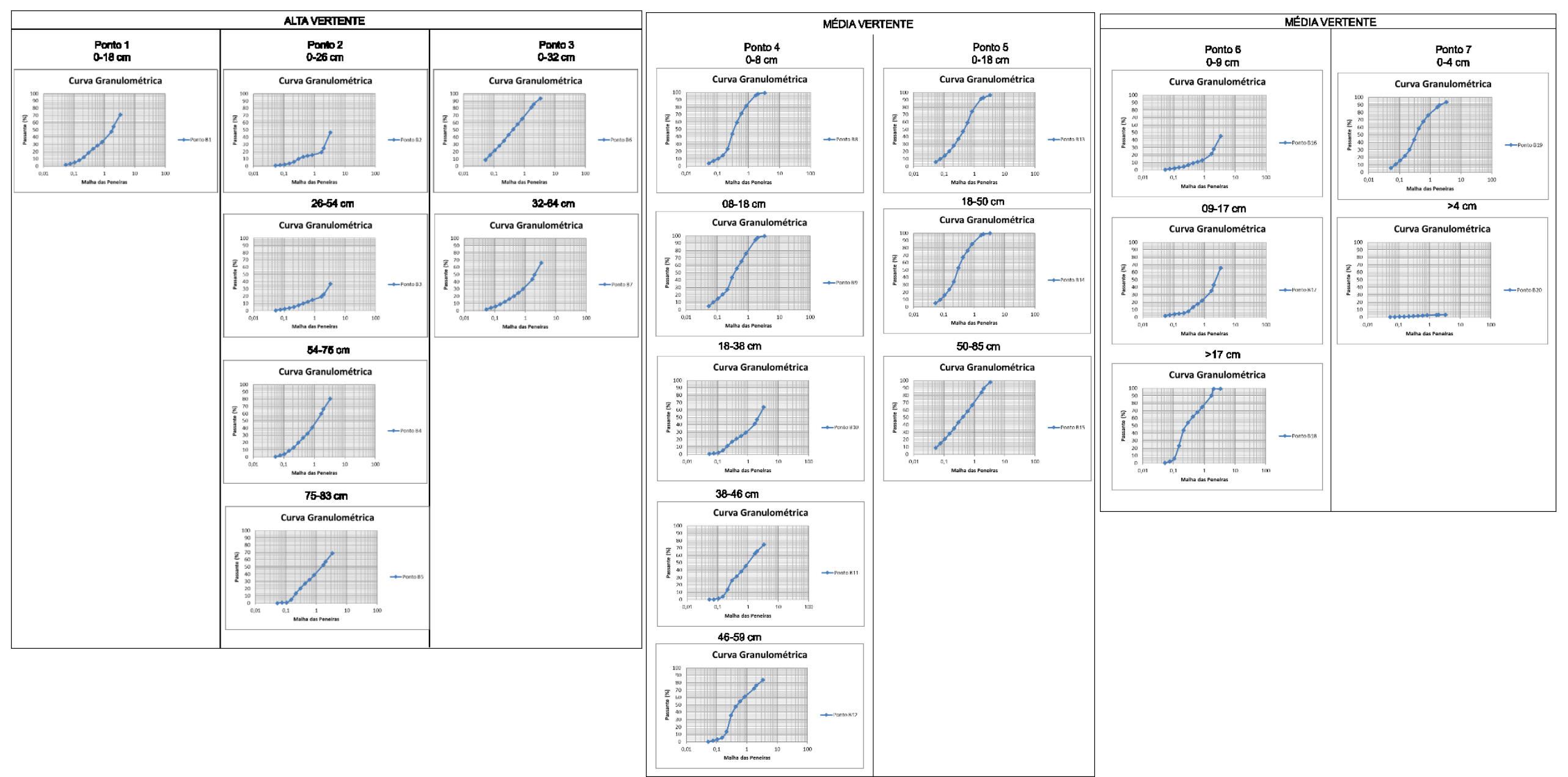

Figura 6 - Curvas granulométricas dos pontos amostrais da Alta e Média Vertentes do Transecto B.

$$
\text { Fonte: Autores, } 2018 .
$$


As amostras de baixa vertente (Figura 7), por sua vez, foram representativas de camadas com materiais mais finos e curvas granulométricas pouco mais contínuas e graduadas, com exceção do ponto 8 na transição da média para a baixa vertente, com presença de concreções ferruginosas, bem como o ponto 9, apresentando uma camada laterítica em profundidade maior que $30 \mathrm{~cm}$. Os pontos 10 a 13 apresentam uma transição de materiais mais finos, areno-argilosos, para orgânicos, bastante profundos e escurecidos.

O fato da existência de materiais cascalhentos e concrecionários nos diferentes níveis topográficos do transecto, bem como em profundidades próximas ou superiores a $30 \mathrm{~cm}$ nas áreas côncavo-retilíneas de baixa vertente, pode estar relacionado a questões de variações no regime hídrico da região, podendo ser associado ao observado no Transecto $\mathrm{A}$, em que se observou a presença de camadas subsuperficiais cascalhentas sotopostas a materiais mais finos. Outro ponto a ser destacado, refere-se à distribuição da presença de $\mathrm{Fe}$ ao longo dos diferentes compartimentos da vertente, permitindo pressupor a perda de $\mathrm{Fe}^{2+}$ dissolvido em água, o qual migra das partes altas para as baixas.

No que se refere às análises granulométricas por sedimentação, a Figura 8 ilustra a distribuição das frações finas dos materiais do Transecto $\mathrm{B}$, indicando maior variação das proporções comparado aos resultados do Transecto A. Na vertente em questão, observa-se um aumento das taxas de silte e argila, porém, as porções arenosas ainda são significativas. Do ponto de vista dos processos, estima-se que essa área reflete maior atuação dos agentes intempéricos, quer através das características do material parental, quer pela presença das camadas ferruginosas e concreções. Assim, pela classificação no triângulo textural, de modo geral, pode-se estabelecer que os materiais são franco-argilo-arenosos. 

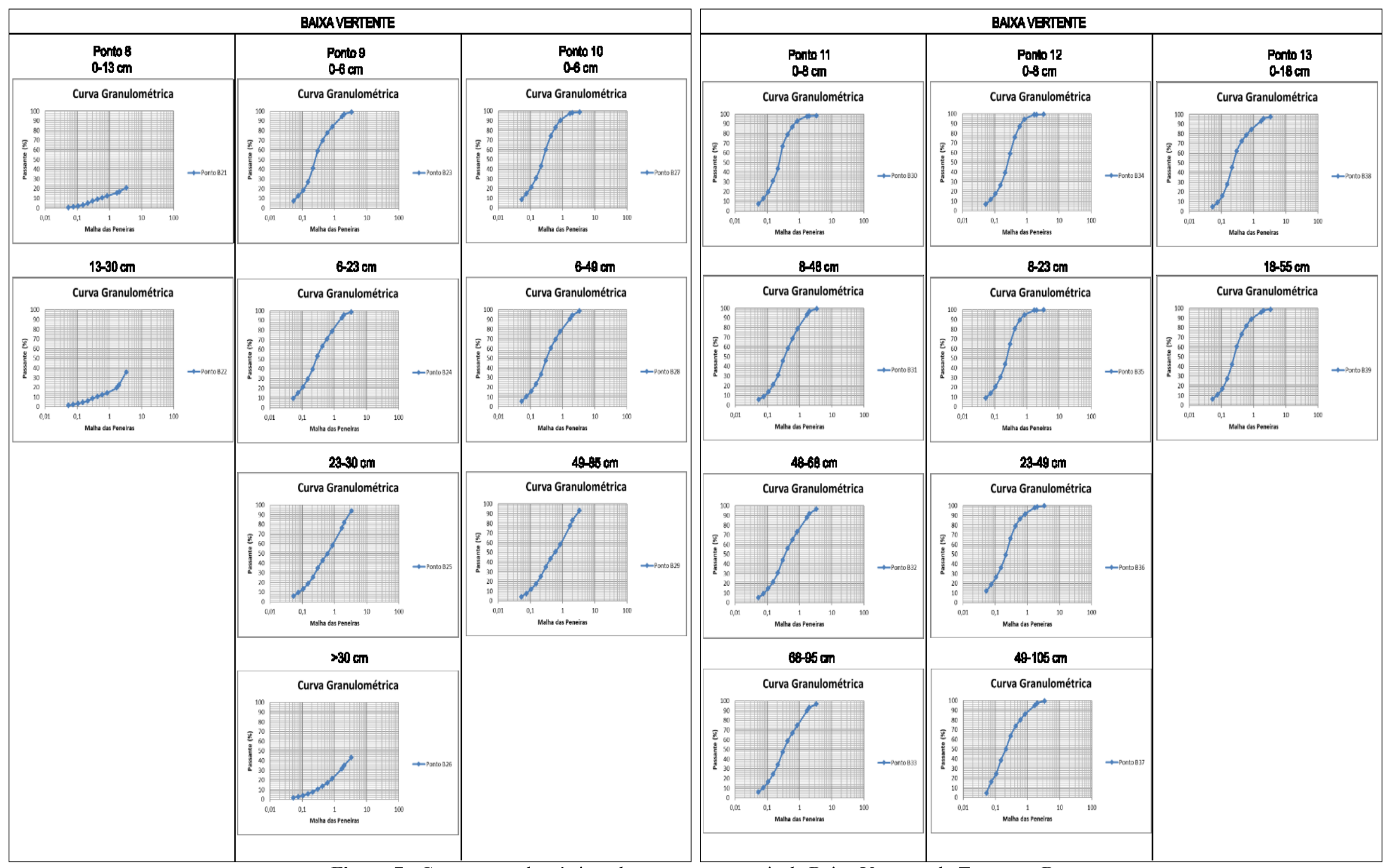

Figura 7 - Curvas granulométricas dos pontos amostrais da Baixa Vertente do Transecto B. Fonte: Autores, 2018 


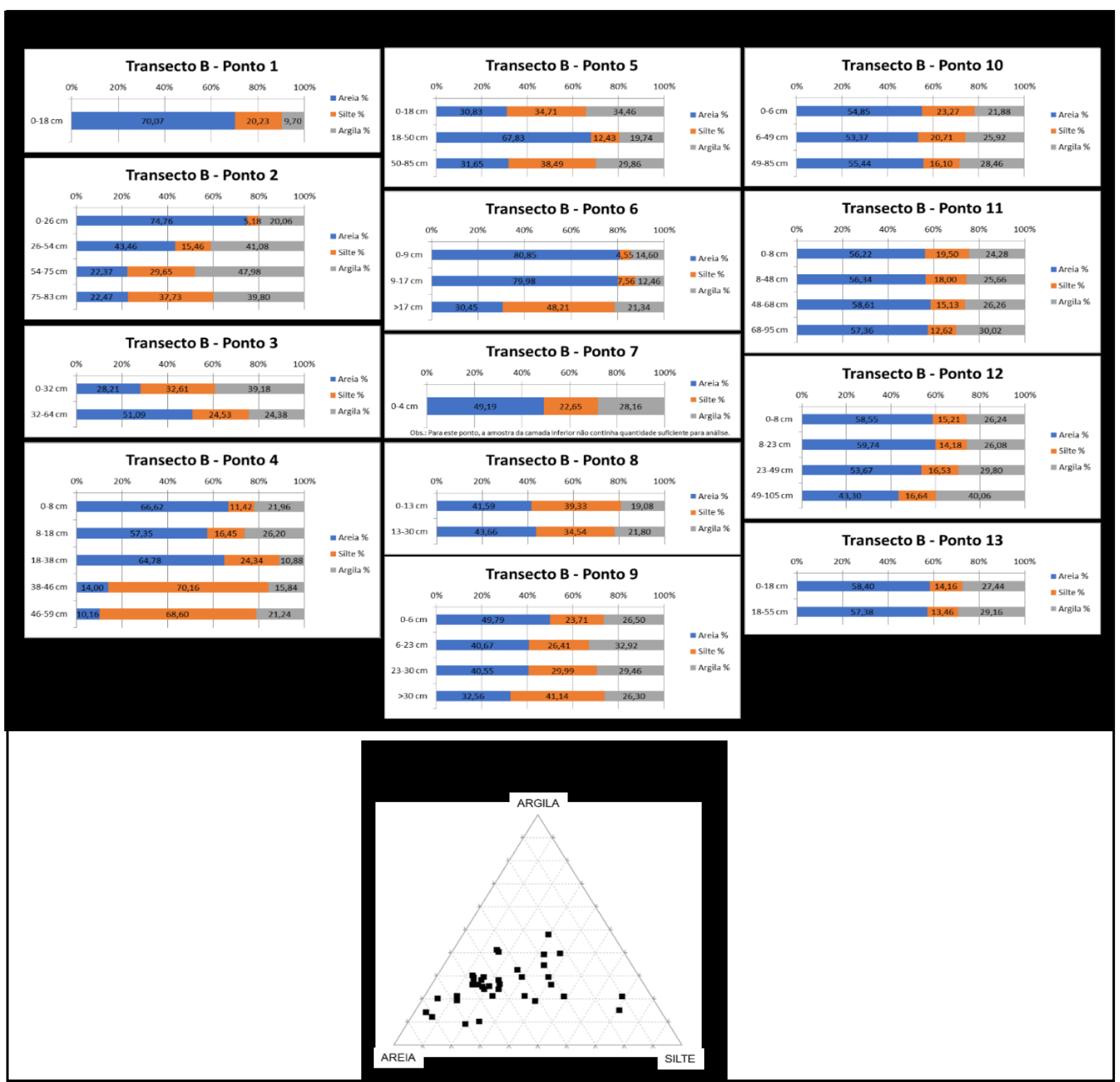

Figura 8 - Conjunto de gráficos e triângulo textural, resultantes da análise de granulometria por sedimentação para o Transecto B (Fonte: Autores, 2018).

\subsection{Transecto $\mathrm{C}$}

A terceira área amostral é caracterizada pelo transecto C (Figura 9), em relevo também aplainado a suavemente dissecado, porém com materiais profundos e com ausência de afloramentos rochosos, os murunduns aparecem na baixa vertente antecedendo os materiais orgânicos do fundo. No geral, os materiais se apresentam uniformes com raras ocorrências de grãos de quartzo envoltos por ferro. Esta vertente possui 200 metros de extensão, sendo convexo-retilínea em sua parte alta e côncavo-retilínea na parte baixa, e está localizada no oeste do ChD. Foram realizados 10 pontos amostrais por meio de tradagens.

Os resultados da análise granulométrica por peneiramento indicaram para este transecto, a ocorrência de curvas relativamente homogêneas nos variados pontos amostrais ao longo da vertente, as quais se apresentam contínuas e bem graduadas. As Figuras 10 e 11 ilustram as curvas granulométricas dos pontos amostrais, as quais não indicaram mudanças abruptas na composição 
física dos materiais. A característica marcante está na profundidade dos perfis, bem como na ausência de materiais cascalhentos como observado nos transectos anteriores. A Vertente C caracteriza-se, portanto, por um maior grau de evolução intempérica, uma vez que apresenta maiores proporções da fração argila, principalmente na área de alta e baixa vertente. Já na média vertente, verificou-se uma proporção mais elevada da fração areia, bem como algumas ocorrências de grãos de cascalho esparsos, às vezes concrecionários.

Em relação às análises granulométricas por sedimentação, estas estão representadas na Figura 12, que traz os gráficos da distribuição das frações finas, bem como a caracterização pelo triângulo textural, a partir do qual define-se que os materiais se constituem predominantemente como argilosos a argilo-arenosos.

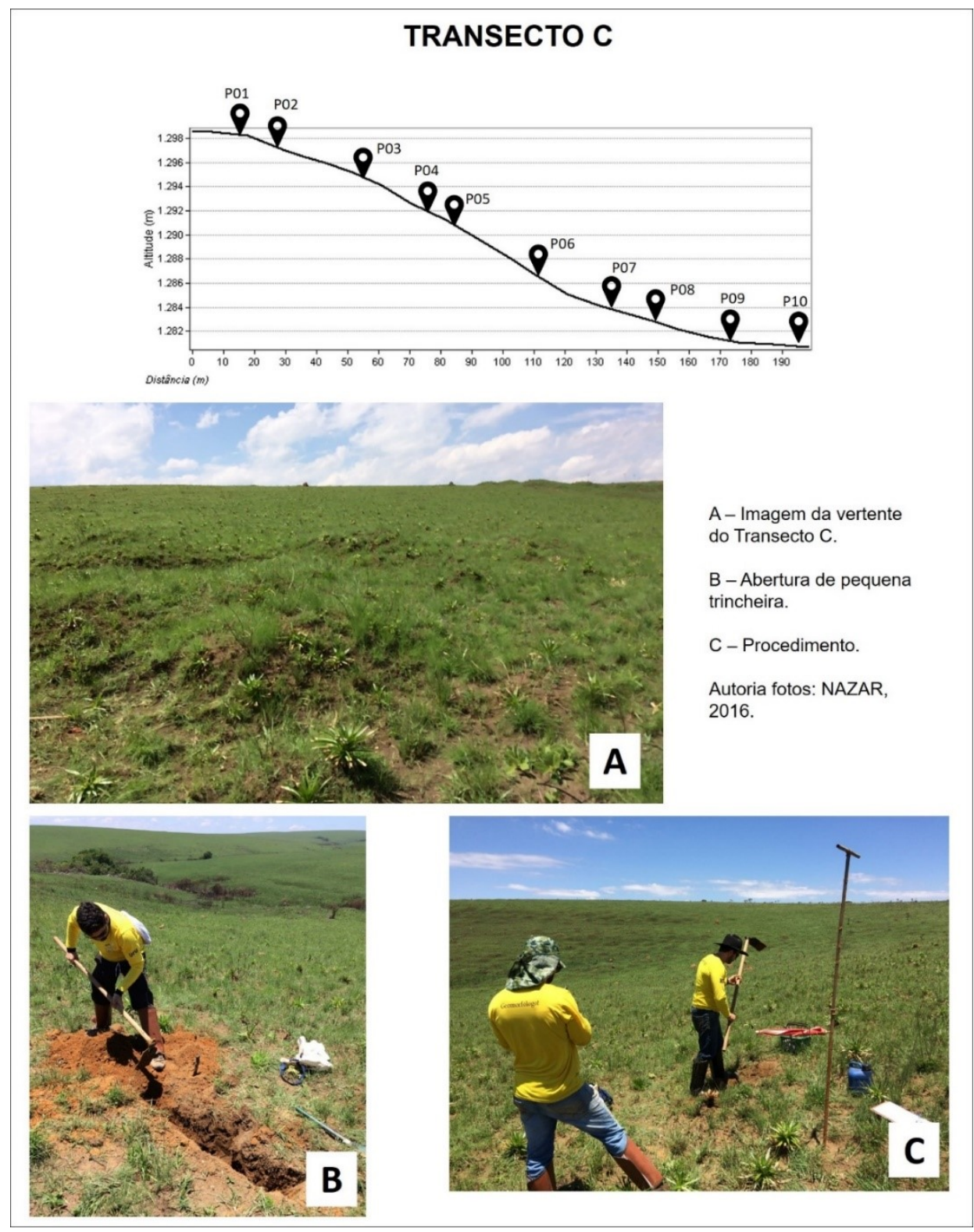

Figura 9 - Transecto $\mathrm{C}$ e pontos amostrais.

Fonte: Autores, 2018 

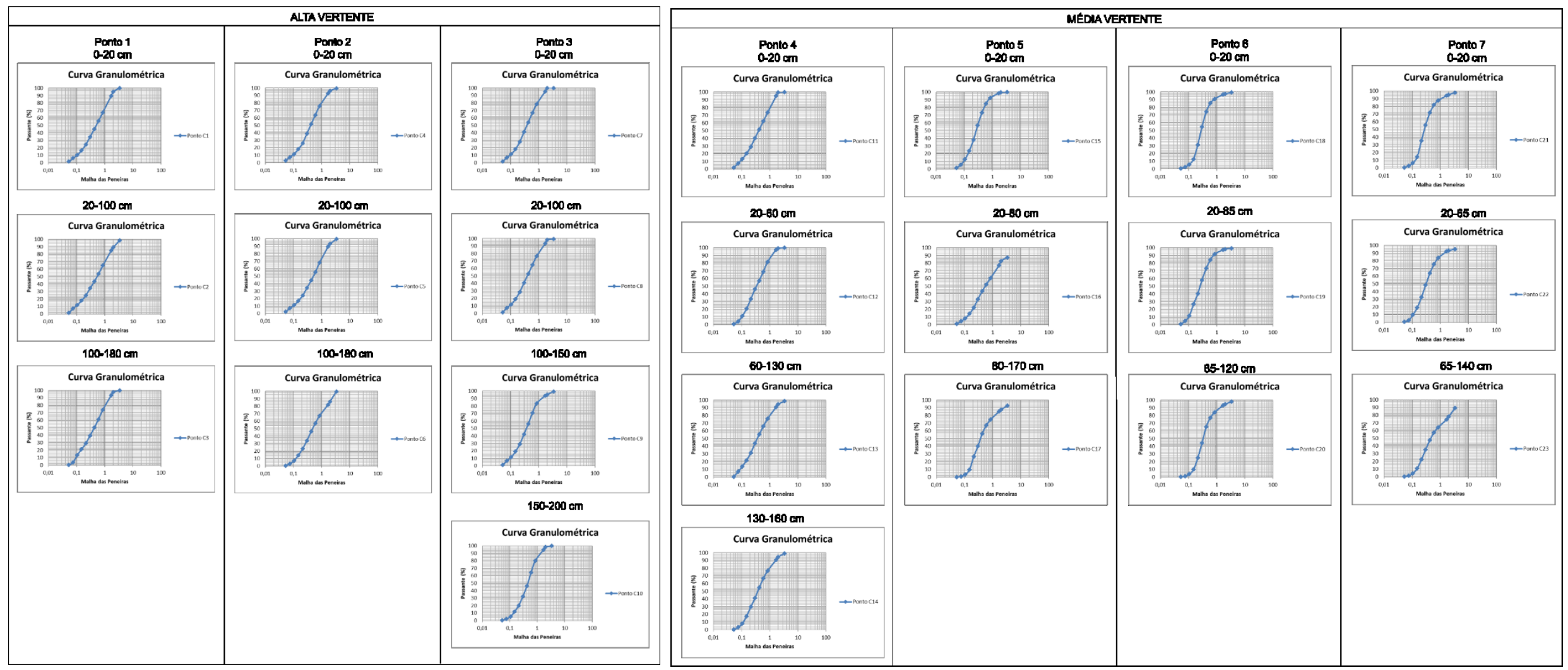

Figura 10 - Curvas granulométricas dos pontos amostrais das Alta e Média Vertentes do Transecto C. Fonte: Autores, 2018. 


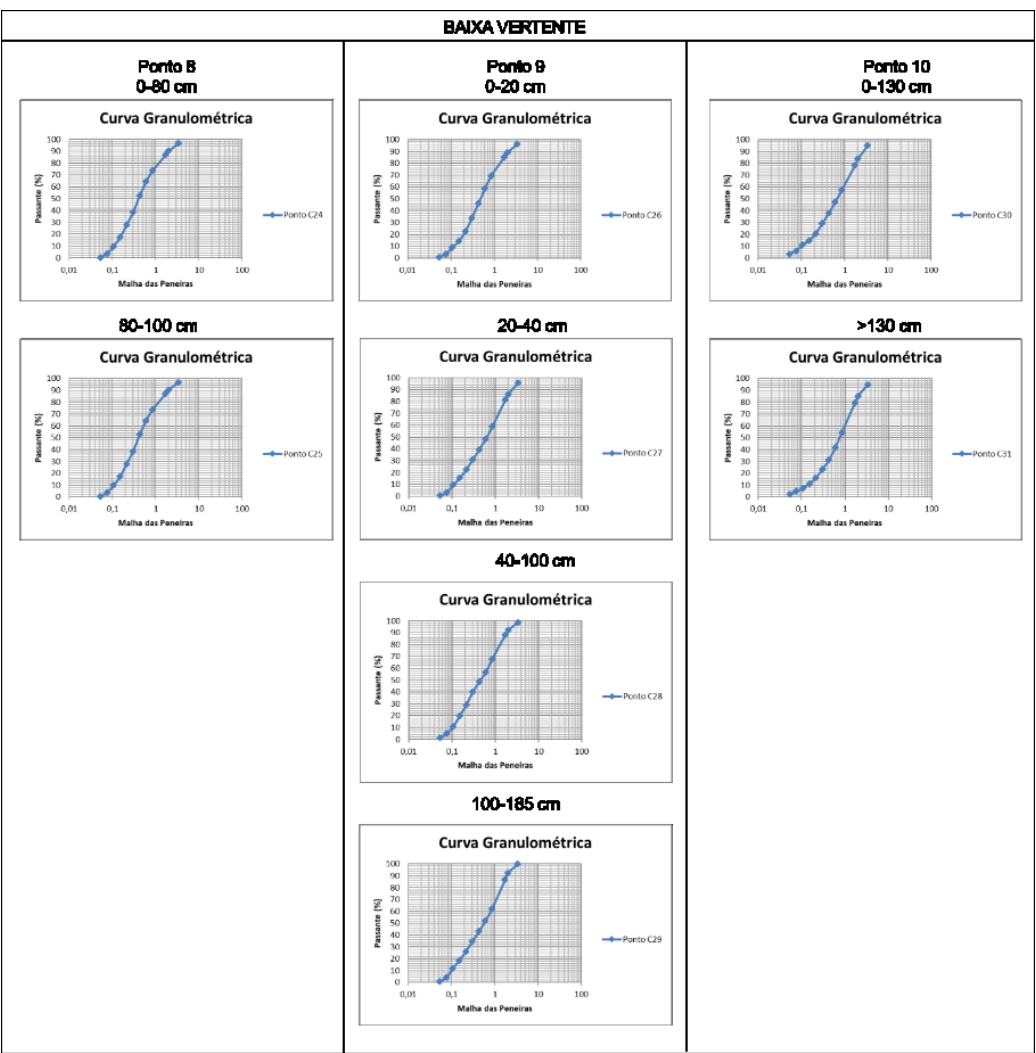

Figura 11 - Curvas granulométricas dos pontos amostrais da Baixa Vertente do Transecto C.

Fonte: Autores, 2018.

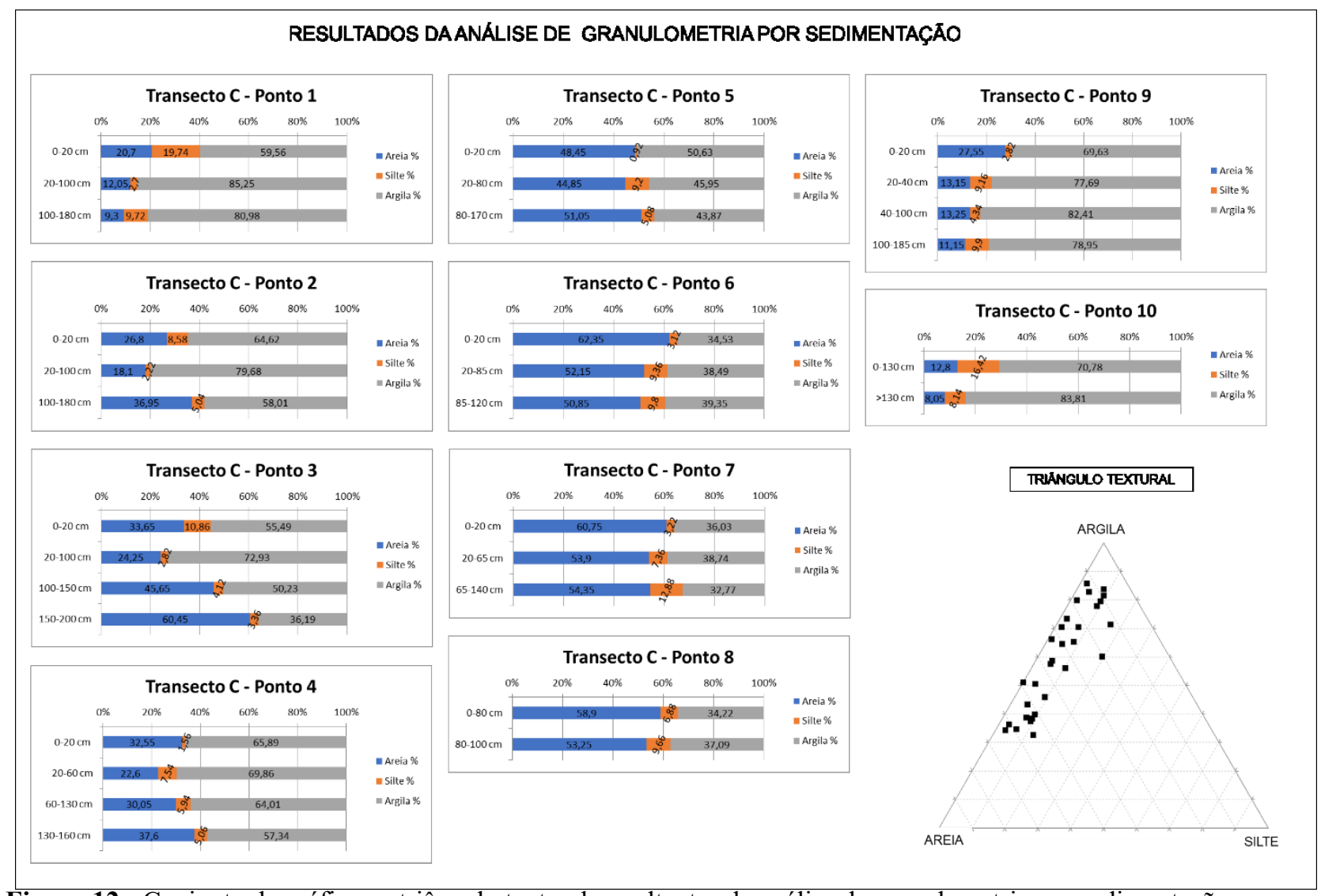

Figura 12 - Conjunto de gráficos e triângulo textural, resultantes da análise de granulometria por sedimentação para o Transecto C (Fonte: Autores, 2018). 


\section{CONSIDERAÇÕES FINAIS}

Ao se comparar as análises granulométricas das três vertentes em questão, é possível confirmar a inter-relação das geocoberturas com os aspectos litológicos e a topografia. Enquanto o Transecto A, caracterizado pela presença de um substrato quartzítico em área de relevo em crista, resultou em geocoberturas bastante arenosas e cascalhentas; o Transecto B, resultou em maior variação granulométrica, apresentando aumento das taxas de silte e argila e presença de concreções ferruginosas, em área de topo plano e vertente mais suave; porém, ambos com perfis rasos ou pouco profundos. No Transecto C, por sua vez, observou-se maior presença de materiais argilosos e perfis mais profundos.

Por outro lado, tanto o Transecto B quanto o C apresentam ocorrência de campos de murunduns e termiteiros ativos, que se distribuem nas áreas de maior permanência de umidade nas camadas de geocoberturas. Suas incidências, em geral, principalmente na zona do Transecto B, configuram as adjacências dos topos aplainados, que ao serem sustentados por concreções ferruginosas, as quais também estão presentes ao longo das vertentes, podem formar um acamamento pouco permeável, mantendo a água subsuperficial por mais tempo.

As observações e análises físicas das três vertentes contribuíram para complementar a ideia de que o Chapadão do Diamante remete ao manejo do equilíbrio entre a resistência do material parental quartzítico e a intensidade do intemperismo. Mesmo no Transecto A, com grande ocorrência de afloramentos rochosos, nos locais amostrais onde foram observadas áreas de deposição, em função das barreiras formadas pelos próprios afloramentos ou em segmentos de vertentes côncavo-retilíneas, os materiais se mostraram em estágio mais avançado, com granulometrias mais finas. Isto indica que o ambiente está há bastante tempo em estabilidade, uma vez que, mesmo em materiais incipientes, formados por processos de transporte por gravidade (materiais coluviais), a atividade pedogenética está presente. A ocorrência de geocoberturas ferruginosas também sugerem a longa exposição aos fatores intempéricos.

Em suma, o presente artigo, por meio dessa análise comparativa de vertentes, contribuiu como parte de uma pesquisa maior na área do Chapadão do Diamante (a tese de doutorado da primeira autora), tendo sido relevante por trazer à tona a resposta granulométrica frente ao papel dos agentes do intemperismo sobre as rochas quartzíticas, evidenciando a relação clima-rocha-relevo, bem como fornecendo dados para o entendimento da área enquanto um sistema geomorfológico. 


\section{AGRADECIMENTOS}

O presente trabalho foi realizado com apoio da Fundação de Amparo à Pesquisa do Estado de Minas Gerais - FAPEMIG, assim, os autores agradecem pelo fomento concedido através do projeto CRA APQ-0231/2016, bem como pela bolsa de Doutorado da primeira autora (PAPG GEOGRAFIA, 2014-2018).

\section{REFERÊNCIAS}

EMBRAPA - EMPRESA BRASILEIRA DE PESQUISA AGROPECUÁRIA. Centro Nacional de Pesquisa de Solos. Manual de métodos de análise de solo. 2. ed. Rio de Janeiro: Embrapa CNPS, 1997. 212p.

- EMPRESA BRASILEIRA DE PESQUISA AGROPECUÁRIA. Padronização de Métodos para Análise Granulométrica no Brasil. Comunicado Técnico 66. Rio de Janeiro: EMPRABA, 2012. 11p.

MESSIAS-MARTINS, R.; AMORIM, M. A. F.; AUGUSTIN; C. H. R. R.; AZEVEDO, P. A. A. Relação entre forma da vertente, cobertura superficial e sítios geomorfológicos na bacia do Ribeirão do Chiqueiro, Depressão de Gouveia, Serra do Espinhaço Meridional - MG. Geonomos, Belo Horizonte, v. 21, n. 2, p. 38-45, 2013.

NAZAR, T. I. S. M. O Chapadão do Diamante na Serra da Canastra/MG, Brasil: caracterização geomorfológica e análise integrada do meio físico a partir de dados multifontes. 2018. 270 f. Tese (Doutorado em Geografia) - Universidade Federal de Uberlândia, Uberlândia, 2018.

NAZAR, T. I. S. M.; RODRIGUES, S. C. Relevo do Chapadão do Diamante, Serra da Canastra/MG, Brasil: compartimentação e análise a partir dos aspectos geomorfométricos. Revista Brasileira de Geomorfologia, v. 20, p. 69-88, 2019a. http://dx.doi.org/10.20502/rbg.v20i1.1300

NAZAR, T. I. S. M.; RODRIGUES, S. C. Mapeamento e Análise de Geocoberturas no Chapadão do Diamante - MG - Brasil. Mercator, Fortaleza, v. 18, p. 1-19, 2019b. http://dx.doi.org/10.4215/rm2019.e18010.

SANTOS, F. C.; RODRIGUES, S. C. Procedimento Operacional Padrão (POP) - Laboratório de Geomorfologia e Erosão de Solos. 30p. Uberlândia, 2019. DOI:10.13140/RG.2.2.11998.59202

SOUZA, D. A.; RODRIGUES, S. C. Aspectos Morfoestruturais da Serra da Canastra e entorno (MG). Revista do Departamento de Geografia - USP, São Paulo, v. 27, p. 47-66, 2014. https://doi.org/10.11606/rdg.v27i0.472 